nucleus, becoming part of its galactic cloud of gas and dust particles. The galaxies are thus continually losing particles to distant galaxies but at the same time gaining particles from other distant galaxies. These particles when moving with speeds close to that of light are considered by Milne to constitute what we know as 'cosmic rays'.

Milne's discussion leads him to the following conclusions. "Laws of motion are not special creations but are indissolubly connected with the creation of the material content of the universe in the only manner in which such creation could have taken place, namely, by the recognition by the Creator of the impossibility of choosing special velocity frames when there is nothing to distinguish one frame from another, and of the impossibility of effecting the act of creation otherwise than at a point-singularity owing to the impossibility of choosing, unambiguously, simultaneous events separated from one another. Creation, the act, became a more and more difficult process the more we study it, until we see how God the Creator put aside the difficulties by the device of the creation of an infinite universe at a point as an initial point-singularity. ... For the creation by God of an extended universe would require an impossibility, the impossibility of the fixation of simultaneity in the void-impossibility, that is, to a rational God. The paradox follows that the Deity himself, though in principle all-powerful, is yet limited by his very rationality. With God all things are not possible. This equally rules out the idea of continuous creation of matter everywhere in space, for there would have to be a pre-created space in which the creation of matter could take place; and there would exist a constant, namely the rate of creation of such matter, which could not be rationally accounted for."

Many readers of this exposition of kinematic relativity will not regard these conclusions as justified. But all will find much that is stimulating and thoughtprovoking in this exposition by its creator of a theory which has provided a searching examination of the concepts of time and space and which has great achievements to its credit. H. SPENCER JonEs

\section{BOTANICAL TAXONOMY}

\section{Taxonomy of Vascular Plants}

By Prof. George H. M. Lawrence. Pp. xiii +823. (New York: The Macmillan Company; London: Macmillan and Co., Ltd., 1951.) 60s. net.

THERE has been a great need for an up-to-date and comprehensive handbook on the classification of vascular plants, and botanists all over the world are grateful to Prof. George Lawrence for undertaking to fill the gap. This he has done with notable judgment and skill, and with, inevitably, the expenditure of much time and labour that could no doubt be ill-spared from his research and other activities. As a result, he has produced a volume that will, for many years, be the daily companion of all concerned with the taxonomy of flowering plants and ferns.

The book is divided into two parts. The first, consisting of fourteen chapters (330 pages), deals with what may be broadly described as the principles and practice of systematic botany, while the second part (400 pages) is concerned with individual families, arranged in the sequence of Engler and Diels. There are two appendixes comprising a suggested syllabus for an elementary course in taxonomy, and an illustrated glossary of terms. An excellent single index completes the volume: Prof. Lawrence has chosen to scatter his very valuable bibliographies throughout the book after the relevant sections, and one thus misses the ease of finding a particular reference afforded by a single alphabetical bibliography, coupled with lists of abbreviated references after each chapter; but the saving of space no doubt dictated his choice, and, as it is, the bibliographies, especially those after each family in Part 2, will be one of the most welcome features of the book.

In Part 1 Prof. Lawrence gives excellent accounts of the history of botanical classification, leading to a survey of current systems, and has chapters on geographical distribution, nomenclature, identification, literature, field work and herbarium techniques, and on the writing of monographs, revisions and Floras. But it is probably to the sections on the more controversial aspects of taxonomy that many readers will turn first, for there are very few easily accessible recent summaries on the relationship between classification and phylogeny (Chapter 5), and on biosystematics and experimental taxonomy (Chapter 8). Prof. Lawrence's two chapters are undoubtedly the clearest and most up-to-date treatments so far produced, and show an awareness of many of the subtle difficulties that are so often ignored. In his discussions in phylogeny and taxonomy, however, and on biosystematics, one misses a clear statement of the basic aims of classification in general, and of biological classification in particular, without which the present troubled state of these subjects can scarcely be resolved. The idea that there can ultimately be one comprehensive classification of living things based on all their characters is a very attractive one to the human mind; but the belief that this concept is chimærical is slowly gaining ground, and a number of biologists are gradually realizing that, in common with all other types of object, animals and plants must be classified in different ways for different purposes. Against the background of this view, morphological, phylogenetic and 'biosystematic' classifications will be seen as systems existing in their own right, for their own particular purposes, rather than as stages owards the final goal of an all-embracing taxonomy of living things. It is to be hoped that, in future editions, Prof. Lawrence will carry his analysis one stage deeper and discuss more fully this borderland region between philosophy and biology.

In the second part of the book a clear and thorough account is given of all the important families of flowering plants and ferns, and, in addition, many other families are mentioned, under their orders, without description. The choice of the sequence of Engler and Diels, because "it is the only available system that has been devised to account in detail for the flora of the world", is a convenient and sensible one. Perhaps the most valuable feature under each order and family is the summary of the phyletic treatment given to it by various authors in the past-information not easily available elsewhere. The text figures illustrating each family add greatly to the usefulness of the descriptions.

Prof. Lawrence has produced one of the most important books for many years in the field of systematic botany, and it is to be hoped that, despite its inevitably high price, it will be widely bought and used by students.
J. S. L. GILMOUR 


\section{X-RAY CRYSTALLOGRAPHY IN TECHNOLOGY}

X-Ray Crystallographic Technology

By Andre Guinier. English translation by T. L. Tippell ; edited by Prof. Kathleen Lonsdale. Pp. xiii $+330+16$ plates. (London: Hilger and Watts, Ltd., 1952.) 56s. net.

$\mathrm{T}$ HIS book was originally published in 1945 and was a good survey of X-ray crystallography as it was at that time. Since then, many developments have occurred which the author has not dealt with; however, the methods have not altered much, and the book forms a good introduction for the university student and research worker.

There are five parts and twelve chapters. The first three chapters are devoted to a study of the general properties of X-rays, the means of producing $X$-rays, and the theory of crystallography and X-ray diffaction. Chapters 4-6 are devoted to powder photographs, single-crystal photographs and the special applications of strictly monochromatic radiation. Chapters 7-9 deal with the determination of texture, chemical identification by measurement of cell dimensions, the study of phase diagrams and of elastic strains by accurate measurements of cell dimensions and, lastly, the study of order - disorder states in metals. The closing chapters, 10-12, deal with crystal imperfections, the diffraction of X-rays by amorphous substances, and the determination. of the size of submicroscopic particles by low-angle scattering. The first appendix contains fundamental theory of X-ray diffraction too difficult to incorporate in the body of the text, and the succeeding appendixes give material such as tables of data about elements and the relation between $\theta$-angles and the spacing for various wave-lengths which can also be found in the standard reference works. A number of plates are provided to illustrate various types of photographs referred to in the preceding chapters.

The book can be recommended as an introduction to the subject, although it is doubtful whether it will satisfy the needs of the technician, to whom the author specifically addresses the book. The omissions of subject-matter which might be expected in a modern book are no doubt partly due to the original time of its production, just after the Second World War, when there was much isolation of the scientific workers in France from those in Britain and other countries. It is almost certain that $\mathrm{X}$-ray crystallographers need to know much more about hightemperature powder cameras, about moving-film cameras of various types, and more about spectrometers and Geiger counters than is here included. The actual description of instruments is, with only one or two exceptions, confined to the principles on which they are constructed. The technician usually requires to know the merits and demerits of various types, and even how ro modify a given type to suit his particular purpose. The treatment given here is too brief and too academic really to serve the technician, though it will be useful to students in general.

There is one innovation which seems unfortunate to me-namely, the introduction of the term 'crystal base' to signify the nature and arrangement of the contents of a unit cell of the crystal. In the German literature 'basis' is firmly established as the correct word; but in Fnglish writing 'basis' has only occasionally been used and usually the word 'structure' serves. A possible objection to the use of the word 'structure' is that it also signifies the nature and arrangement of the atoms in the whole crystal, though this ambiguity is not usually a serious difficulty. There are, however, weighty objections to the use of the word 'base'. It has the ordinary meaning of 'lower surface', and if the term 'base' is introduced, as in this book, it will be necessary, for example, to make a confusing statement such as "the base of sodium chloride contains four sodium and four chlorine atoms". Further, the plane (001) is invariably referred to as the 'basal plane', and hence the 'base' in morphology means this plane. If the term 'crystal structure' is not adequate, perhaps 'unit-structure', 'cell-structure' or 'cell-assembly' might be used.

The production of the text, tables and photographs is excellent, and there appear to be few misprints. W. A. Wooster

\section{PSYCHOPATHOLOGY OF GENIUS}

The Infirmities of Genius

By Dr. W. R. Bett. (Medical Viewpoint Series.) Pp. $182+6$ plates. (London: Christopher Johnson (Publishers), Ltd., 1952.) 18s. net.

$\mathrm{TN}$ this book, parts of which have already appeared in Clinical Excerpts, Dr. W. R. Bett sets out to describe briefly the lives of fifteen men of genius and to relate their mental activity to the various afflictions which beset them. Beginning with Carlyle, whose neurasthenia he attributes to dyspepsia, he proceeds to discuss, among others, Shelley, Whitman, Swinburne, Baudelaire, Burns, Byron, Pope and Lafcadio Hearn. In every case he shows that there can be little doubt that the maladies from which his subjects suffered influenced their literary output and their relation to the society in which they lived. This is what would be expected, and Dr. Bett's treatment of his cases is too slight to enable the reader to consider the much more difficult problem of the precise relation that genius itself bears to the medical history of each individual.

There is no doubt that the literary output of such persons as Byron, Pope or Baudelaire was highly coloured by their infirmities; but these misfortunes were merely those which affect many others and which are clearly not related to genius itself. What is more probable is that the man of genius is likely to suffer from psychosomatic complaints which arise from the very fact of his genius setting him somewhat apart from his fellows; and, indeed, the examples chosen by Dr. Bett would seem to some to suggest this, although the cruder physical deformities naturally played their part in moulding the general attitude of those suffering from them.

What has to be distinguished is genius itself (whatever this may be) and the results of that genius as seen in literary and artistic production. How far such production proceeds purely from the conscious mind or is related to subliminal processes engendered by alcohol or drugs, as seems to have been the case with De Quincey and Coleridge, we do not know. It seems clear from Dr. Bett's intriguing study that, in the cases he cites, genius, although at times hampered and restrained, was able to surmount infirmity and add much without which the world would be considerably the poorer.
E. J. Dingwall 